University of Nebraska - Lincoln DigitalCommons@University of Nebraska - Lincoln

Faculty Publications in Food Science and

Technology

Food Science and Technology Department

5-28-2019

Nitrogen, Cobalt Co-doped Fluorescent Magnetic Carbon Dots as Ratiometric Fluorescent Probes for Cholesterol and Uric Acid in Human Blood Serum

Shan Huang

Erli Yang

Jiandong Yao

$\mathrm{Xu}$ Chu

Yi Liu

See next page for additional authors

Follow this and additional works at: https://digitalcommons.unl.edu/foodsciefacpub Part of the Food Science Commons

This Article is brought to you for free and open access by the Food Science and Technology Department at DigitalCommons@University of Nebraska Lincoln. It has been accepted for inclusion in Faculty Publications in Food Science and Technology by an authorized administrator of DigitalCommons@University of Nebraska - Lincoln. 
Authors

Shan Huang, Erli Yang, Jiandong Yao, Xu Chu, Yi Liu, Yue Zhang, and Qi Xiao 


\title{
Nitrogen, Cobalt Co-doped Fluorescent Magnetic Carbon Dots as Ratiometric Fluorescent Probes for Cholesterol and Uric Acid in Human Blood Serum
}

\author{
Shan Huang, ${ }^{\dagger, \ddagger \odot}$ Erli Yang, ${ }^{\dagger}$ Jiandong Yao, ${ }^{\dagger}$ Xu Chu, ${ }^{\dagger}$ Yi Liu, ${ }^{\dagger}$ Yue Zhang, ${ }^{\ddagger}$ and Qi Xiao ${ }^{*}{ }^{\dagger}$ \\ ${ }^{\dagger}$ Guangxi Key Laboratory of Natural Polymer Chemistry and Physics, College of Chemistry and Materials, Nanning Normal \\ University, 175 Mingxiu East Road, Nanning 530001, P. R. China \\ ${ }^{\ddagger}$ Department of Food Science and Technology, University of Nebraska-Lincoln, 270 Food Innovation Center, Lincoln, Nebraska \\ 68588, United States
}

Supporting Information

\begin{abstract}
Detection of cholesterol and uric acid biomarkers is of great importance for clinical diagnosis of several serious diseases correlated with their variations in human blood serum. In this study, a new kind of well selective and highly sensitive ratiometric fluorescent probe for cholesterol and uric acid determination in human blood serum was innovatively developed on the basis of the inner filter effect (IFE) process of nitrogen, cobalt co-doped carbon dots ( $\mathrm{N}, \mathrm{Co}-\mathrm{CDs})$ with 2,3-diaminophenazine (DAP). DAP was the oxidative product during the oxidation reaction between $o$ phenylenediamine and $\mathrm{H}_{2} \mathrm{O}_{2}$. Fluorescent magnetic N,Co-CDs possessing blue emission and magnetic property were prepared through a facile one-pot hydrothermal strategy by using citric acid, diethylenetriamine, and cobalt(II) chloride hexahydrate as precursors. N,Co-CDs exhibited good ferromagnetic property and excellent optical properties even in extremely harsh environmental conditions, implying the huge potential applications of such $\mathrm{N}, \mathrm{Co}-\mathrm{CDs}$ in biological areas. On the basis of the IFE process between $\mathrm{N}, \mathrm{Co}-\mathrm{CDs}$ and $\mathrm{DAP}, \mathrm{N}, \mathrm{Co}-\mathrm{CDs}$ were applied to establish ratiometric fluorescent probes for the indirect detection of cholesterol and uric acid that participated in enzyme-catalyzed $\mathrm{H}_{2} \mathrm{O}_{2}$-generation reactions. The established IFEbased fluorescent probes exhibited relatively low detection limits of $3.6 \mathrm{nM}$ for cholesterol and $3.4 \mathrm{nM}$ for uric acid, respectively. The fluorescent probe was successfully utilized for the determination of cholesterol and uric acid in human blood serum with satisfying results, which provided an informed perspective on the applications of such doped CDs to explore the specific and sensitive nanoprobe in disease diagnoses and clinical therapy.
\end{abstract}

\section{INTRODUCTION}

As a rising star of functional carbon-based nanomaterial family, carbon dots (CDs) have attracted numerous concerns in biosensing, cell imaging, and nanomedicine due to their unique photochemical properties, good photostability, and superior biocompatibility. ${ }^{1,2}$ Due to the facile manipulating feature of heteroatom-doped CDs, metal element-doped CDs become a promising powerful strategy to enhance the photochemical performances and enlarge the potential application capabilities of CDs. ${ }^{3-6}$ Recently, some strategies are developed to prepare transition-metal element-doped CDs for different biological applications. ${ }^{7,8}$ Yao et al. explored magnetofluorescent CDs for targeted dual-modality cellular imaging and important drug delivery. ${ }^{9}$ Jia et al. constructed magnetofluorescent CDs for bimodal cellular imaging and photodynamic therapy. ${ }^{10}$ Besides these, magnetic CDs exhibit strong ability in trapping and extracting pathogenic bacteria and cancer cells from complicated sample matrixes, showing potential biological applications in disease diagnosis and cancer therapy. ${ }^{11,12}$ Due to the superior biological safety and good magnetic property of Co element, Co element has been widely selected to dope into CDs for obtaining fluorescent and/or magnetic CDs for magnetofluorescent dual-modality bioimaging. ${ }^{8,13}$ On the other hand, nonmetal $\mathrm{N}$ element is also the frequently used element to efficiently improve the photochemical property of CDs. ${ }^{14}$ Although nonmetal $\mathrm{N}$ element and metal Co element exhibit the most preferable influences on the optical and magnetic properties of CDs and thus on their biological application performances, synthetic pathways toward fluorescent magnetic $\mathrm{N}$ and Co co-doped CDs (N,Co-CDs) are still rare. As far as we know, relative biological application of fluorescent magnetic N,Co-CDs in sensing areas is never reported. It is very necessary to create a cost-efficient and highoutput synthesis strategy for producing fine fluorescent

Received: March 29, 2019

Accepted: May 14, 2019

Published: May 28, 2019 
magnetic N,Co-CDs with superior optical-magnetic property and explore their photochemical properties and potential applications in biosensing.

Cholesterol and uric acid are essential and important biomarkers in the clinical diagnosis of several serious diseases correlated with their changes in human blood serum. ${ }^{15} \mathrm{~A}$ higher amount of cholesterol in blood is usually associated with nephrosis and diabetes mellitus and so on, but a lower amount of cholesterol in blood is often related with anemia, hyperthyroidism, Alzheimer's disease and so on. ${ }^{16,17}$ Moreover, an extra high amount of uric acid in blood is closely related with metabolic disorders but an extra low amount of uric acid may cause some serious diseases. ${ }^{18,19}$ Therefore, monitoring of the cholesterol and uric acid levels in human blood serum is much important for the diagnosis of several serious diseases. Numerous analytical methods were explored for the detection of cholesterol and uric acid in different biological samples, including electroanalysis, ${ }^{20,21}$ surface plasmon resonance, ${ }^{22}$ chemiluminescence, $^{23}$ field effect transistor, ${ }^{24}$ and liquid chromatograph. ${ }^{25}$ Although these methods can effectively detect cholesterol and uric acid in several samples, the requirement of expensive equipments and complicated sample pretreatments limit their applications for simple and rapid determination. So, the exploration of rapid, economic, sensitive, and effective detection strategies for the detection of cholesterol and uric acid in human blood serum becomes a vital public health objective.

Cholesterol and uric acid can be catalyzed by their specific enzymes to produce $\mathrm{H}_{2} \mathrm{O}_{2}$, so it is possible to develop efficient strategies for the detection of $\mathrm{H}_{2} \mathrm{O}_{2}$ that can be used for the indirect quantification of cholesterol and uric acid. More attention has been unremittingly paid to the indirect detection of cholesterol and uric acid through enzyme-catalyzed $\mathrm{H}_{2} \mathrm{O}_{2}$ generation reactions recently, ${ }^{16-19}$ since such strategies can avoid influence from coexisting substances. Ratiometric fluorescence strategy allows the simultaneous measuring of the ratio variations in two well-resolved fluorescent intensities under one excitation wavelength. ${ }^{26,27}$ Such ratiometric fluorescence measurement can omit the drawback from single fluorescence measurement efficiently and improve the sensitivity of the fluorescent assay drastically, resulting in the exploitation of the practical applications of carbon-based nanomaterials in biological areas. ${ }^{28-30}$ However, nonmetal element and metal element co-doped fluorescent magnetic $\mathrm{CDs}$ are rarely utilized as ratiometric fluorescent probes for the detection of cholesterol and uric acid through monitoring $\mathrm{H}_{2} \mathrm{O}_{2}$ amount. Due to the good photochemical properties of nonmetal element and metal element co-doped fluorescent magnetic CDs, it is valuable and meaningful to establish doped CD-based ratiometric fluorescent probes for specific and sensitive detections of cholesterol and uric acid taking part in enzyme-catalyzed $\mathrm{H}_{2} \mathrm{O}_{2}$-generation reactions.

Inspired by such a situation, we innovatively designed fluorescent magnetic N,Co-CDs as a ratiometric fluorescent probe for cholesterol and uric acid detections in human blood serum. As shown in Scheme 1, citric acid (CA), cobalt(II) chloride hexahydrate $\left(\mathrm{CoCl}_{2} \cdot 6 \mathrm{H}_{2} \mathrm{O}\right)$, and diethylenetriamine (DETA) were used as precursors for the convenient synthesis of fluorescent magnetic N,Co-CDs through realizable one-pot hydrothermal method for the first time. Because of the codoping of nonmetal $\mathrm{N}$ element and metal Co element, N,CoCDs possess excellent optical properties and good ferromagnetic property. In the detection process, colorless $o$-phenyl-
Scheme 1. Schematic Illustration of the Preparation of Fluorescent Magnetic N,Co-CDs and Detection Processes of Cholesterol and Uric Acid

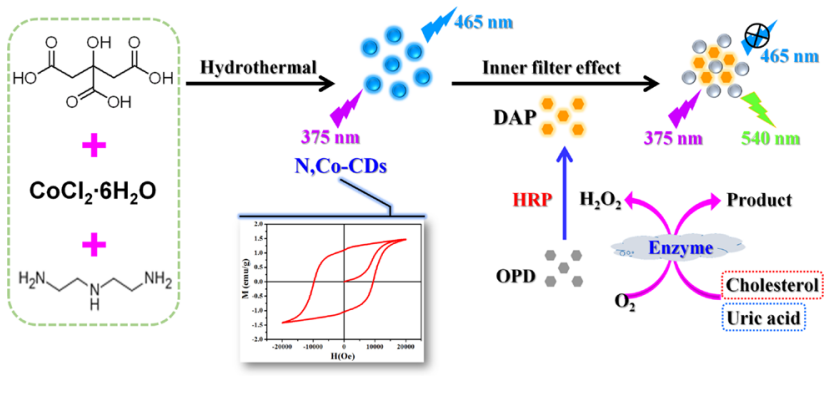

enediamine (OPD) can be oxidized by $\mathrm{H}_{2} \mathrm{O}_{2}$ under the catalysis of horseradish peroxidase (HRP) to produce fluorescent 2,3-diaminophenazine (DAP). Since the absorption spectrum of DAP can partially overlap with the emission spectrum of N,Co-CDs, DAP can quench the fluorescence of $\mathrm{N}, \mathrm{Co}$-CDs through the inner filter effect (IFE) mechanism. As a consequence, an ultrasensitive and highly selective ratiometric fluorescence universal platform toward cholesterol and uric acid involved in enzyme-catalyzed $\mathrm{H}_{2} \mathrm{O}_{2}$-generation reactions was developed. To the best of our knowledge, this is the first but selective and sensitive assay for cholesterol and uric acid determination through the IFE process between fluorescent magnetic N,Co-CDs and DAP, which is identified as a valuable strategy in biomarker-related disease diagnosis and clinical therapy.

\section{RESULTS AND DISCUSSION}

2.1. Structure Characterizations of N,Co-CDs. As illustrated in Figure 1a, N,Co-CDs present a primary orbicular shape and spread around evenly without obvious aggregation in transmission electron microscopy (TEM). According to the statistical analysis of around 200 particles, the sizes of N,CoCDs are in the range from 2.0 to $4.8 \mathrm{~nm}$ and the average size is $3.37 \mathrm{~nm}$ (insert in Figure 1a), implying the relative smaller size of N,Co-CDs than those of other reported N-CDs. ${ }^{15,31}$ These $\mathrm{N}, \mathrm{Co}-\mathrm{CD}$ s possess a clear lattice structure and a discernible lattice spacing of approximately $0.21 \mathrm{~nm}$ (insert in Figure 1a), which is highly consistent with the value of the (100) planes of graphitic carbon. ${ }^{32}$ As indicated in Figure $1 \mathrm{~b}$, the X-ray diffraction (XRD) pattern of N,Co-CDs shows an intense diffraction peak $2 \theta$ at $24.5^{\circ}$ that is often correlated with the $\mathrm{C}(002)$ plane and the poor diffraction peak $2 \theta$ at $42.5^{\circ}$ is assigned to the $C(100)$ plane, respectively. ${ }^{33}$ According to the Bragg equation, ${ }^{34}$ the interlayer distance ( $d$-spacing value) can be calculated to be 0.36 and $0.21 \mathrm{~nm}$ for the diffraction peaks of $\mathrm{C}(002)$ plane and $\mathrm{C}(100)$ plane, respectively, which matches well with the results obtained from the high-resolution TEM (HRTEM).

The structure and functional groups of N,Co-CDs were continuously characterized by Fourier transform infrared spectroscopy (FT-IR). As indicated in Figure 2a, two intense absorption peaks at 3370 and $3058 \mathrm{~cm}^{-1}$ are probably associated with the characteristic stretching vibrations of $\mathrm{O}-$ $\mathrm{H} / \mathrm{N}-\mathrm{H}$ and $\mathrm{C}-\mathrm{H}$, respectively. ${ }^{13,15}$ Three absorption peaks located at 1705,1647 , and $1558 \mathrm{~cm}^{-1}$ are associated with the stretching vibrations of $\mathrm{C}=\mathrm{O}$, multiple $=\mathrm{C}-\mathrm{H}$, and $\mathrm{C}=\mathrm{C}$ bonds, respectively. ${ }^{6,15}$ Two absorption peaks located at 1428 and $1246 \mathrm{~cm}^{-1}$ are ascribed to the stretching vibrations of C- 

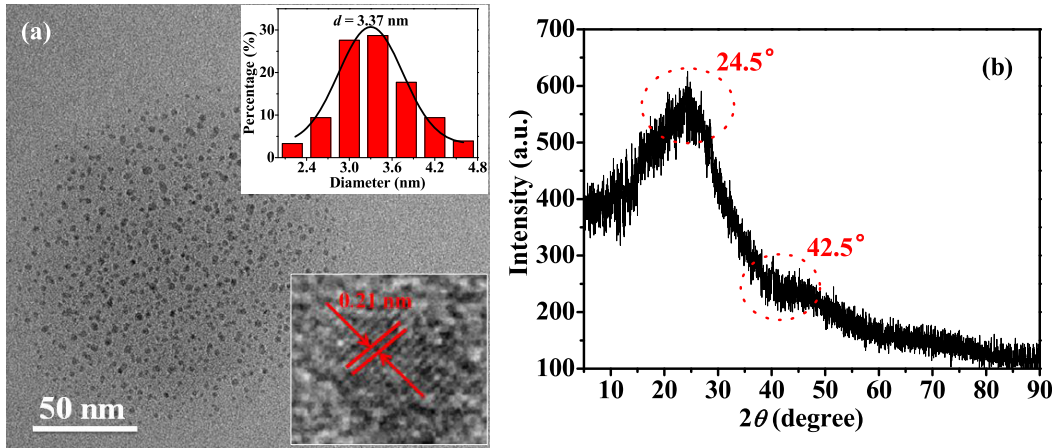

Figure 1. (a) TEM image of N,Co-CDs. Insert: HRTEM image and particle size distribution curve of N,Co-CDs. (b) XRD pattern of N,Co-CDs.
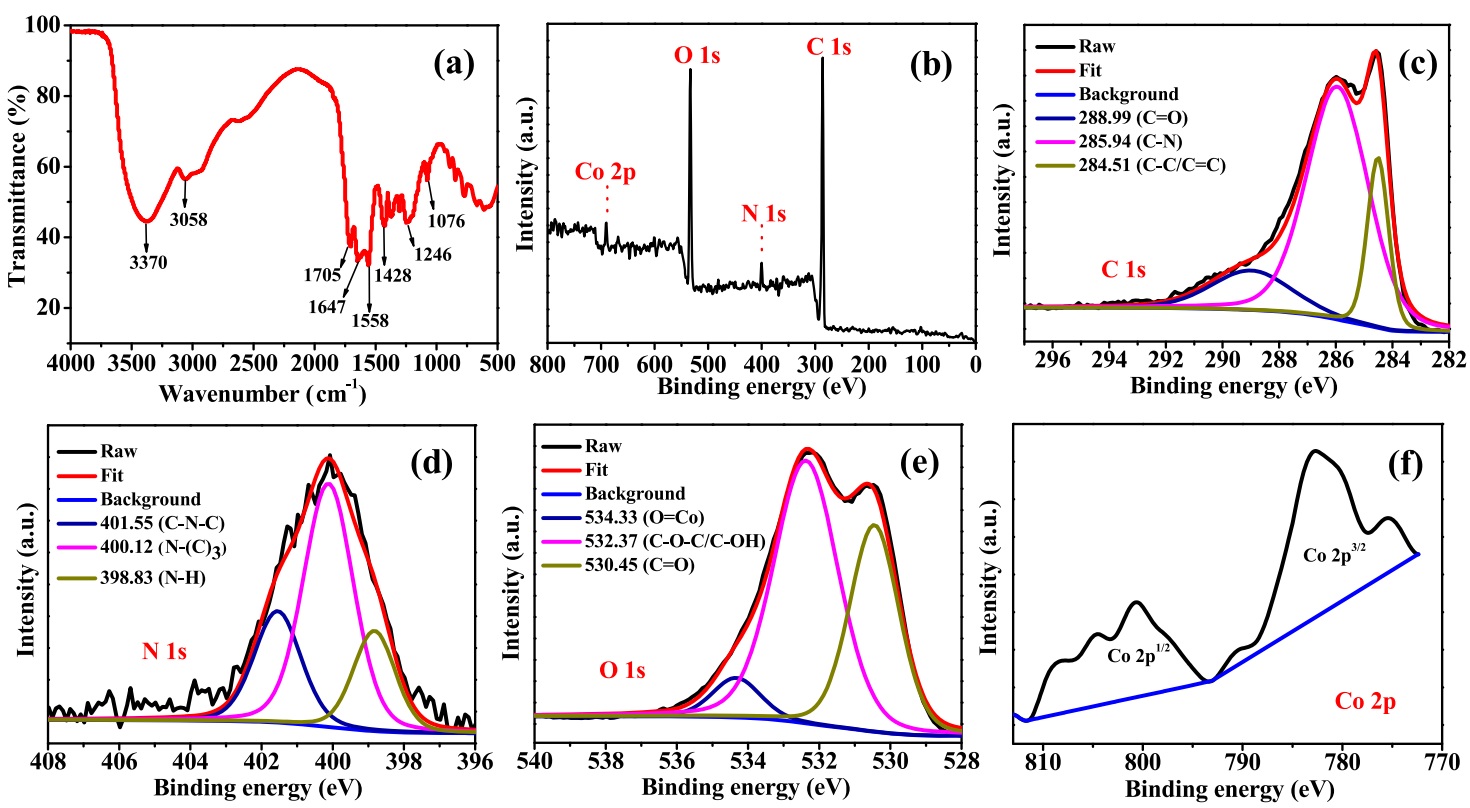

Figure 2. (a) FT-IR spectrum of N,Co-CDs. (b) X-ray photoelectron spectroscopy (XPS) survey spectrum, (c) C 1s XPS spectrum, (d) N 1s XPS spectrum, (e) O 1s XPS spectrum, and (f) Co 2p XPS spectrum of N,Co-CDs.

$\mathrm{N}$ and $\mathrm{C}-\mathrm{O}$ bonds, respectively. ${ }^{15}$ The absorption peak at $1033 \mathrm{~cm}^{-1}$ is ascribed to the stretching vibration of $\mathrm{C}-\mathrm{O}-\mathrm{C}$ bond. ${ }^{35}$ All of these results imply the existences of multiple oxygenated and nitrous functional groups in N,Co-CDs, suggesting their biological applications in targeted drug delivery during clinical therapy.

Detailed surface composition and elemental contents of N,Co-CDs were investigated by X-ray photoelectron spectroscopy (XPS). As shown in Figure 2b, the XPS survey spectrum of N,Co-CDs clearly exhibits characteristic peaks of C $1 \mathrm{~s}$ at $284.9 \mathrm{eV}, \mathrm{N} 1 \mathrm{~s}$ at $400.0 \mathrm{eV}, \mathrm{O} 1 \mathrm{~s}$ at $531.8 \mathrm{eV}$, and $\mathrm{Co} 2 \mathrm{p}$ at $782.5 \mathrm{eV}$, respectively. High-resolution XPS spectrum of $\mathrm{C} 1 \mathrm{~s}$ is divided into three contributions (Figure 2c), including $\mathrm{C}=$ $\mathrm{C} / \mathrm{C}-\mathrm{C}$ at $284.51 \mathrm{eV}, \mathrm{C}-\mathrm{N}$ at $285.94 \mathrm{eV}$, and $\mathrm{C}=\mathrm{O}$ at 288.99 $\mathrm{eV}$, respectively. ${ }^{32,36}$ High-resolution XPS spectrum of $\mathrm{N}$ 1s shows three contributions at 401.55, 400.12, and $398.83 \mathrm{eV}$ (Figure 2d), which are attributed to $\mathrm{C}-\mathrm{N}-\mathrm{C}, \mathrm{N}-(\mathrm{C})_{3}$, and $\mathrm{N}-\mathrm{H}$, respectively. ${ }^{31}$ High-resolution XPS spectrum of $\mathrm{O} 1 \mathrm{~s}$ shows three contributions at 534.33, 532.37, and $530.45 \mathrm{eV}$ (Figure 2e), ascribing to $\mathrm{Co}=\mathrm{O}, \mathrm{C}-\mathrm{O}-\mathrm{C} / \mathrm{C}-\mathrm{OH}$, and $\mathrm{C}=$ $\mathrm{O}$, respectively. ${ }^{13}$ From the high-resolution XPS spectrum of Co $2 \mathrm{p}$ (Figure 2f), Co $2 \mathrm{p}_{3 / 2}$ at $782.80 \mathrm{eV}$ and Co $2 \mathrm{p}_{1 / 2}$ at $800.60 \mathrm{eV}$ are assigned to its spin-orbit splitting ${ }^{13}$ and the binding energies of 790.60 and $804.50 \mathrm{eV}$ are ascribed to their shake-up resonance transitions, respectively. All of these results provide a strong evidence of the existence of $\mathrm{Co}^{2+}$ ions in the obtained N,Co-CDs backbone. ${ }^{13}$ According to the result of the elemental analysis, N,Co-CDs are composed of C $38.90 \mathrm{wt} \%$, H 7.63 wt \%, N 18.94 wt \%, Co 8.06 wt \%, and O (calculated) 26.47 wt \% (Table S1a) and the empirical formula of N,CoCDs is approximately $\mathrm{C}_{25} \mathrm{H}_{56} \mathrm{~N}_{10} \mathrm{CoO}_{12}$ (Table $\mathrm{S} 1 \mathrm{~b}$ ). All of these results reconfirm not only the successful doping of $\mathrm{N}$ and Co elements in N,Co-CDs but also the existences of multiple oxygenated and nitrous functional groups in these N,Co-CDs.

2.2. Optical and Magnetic Properties of N,Co-CDs. As shown in Figure 3a, N,Co-CDs show an evident UV-vis absorption peak at $240 \mathrm{~nm}$ corresponding to the $\pi \rightarrow \pi^{*}$ electronic transition of aromatic $\mathrm{sp}^{2}$ carbon. ${ }^{15}$ The typical absorption peak at $357 \mathrm{~nm}$ is assigned to the $\mathrm{n} \rightarrow \pi^{*}$ electronic transitions of $\mathrm{C}=\mathrm{O}, \mathrm{C}=\mathrm{N}$, and other bonds in N,Co-CDs, resulting in these $\mathrm{N}, \mathrm{Co}-\mathrm{CDs}$ emitting strong blue fluorescence under a handheld UV lamp with $365 \mathrm{~nm}$ wavelength (insert in Figure 3a). ${ }^{37-39}$ These N,Co-CDs emit blue fluorescence according to the Commission International d'Eclairage (CIE) $19312^{\circ}$ chromaticity diagram (Figure S1). ${ }^{40}$ As further shown in Figure $3 b, c$, the emission wavelength of N,Co-CDs redshifts from 435 to $475 \mathrm{~nm}$ with the excitation wavelength increasing from 320 to $420 \mathrm{~nm}$, suggesting the emission 

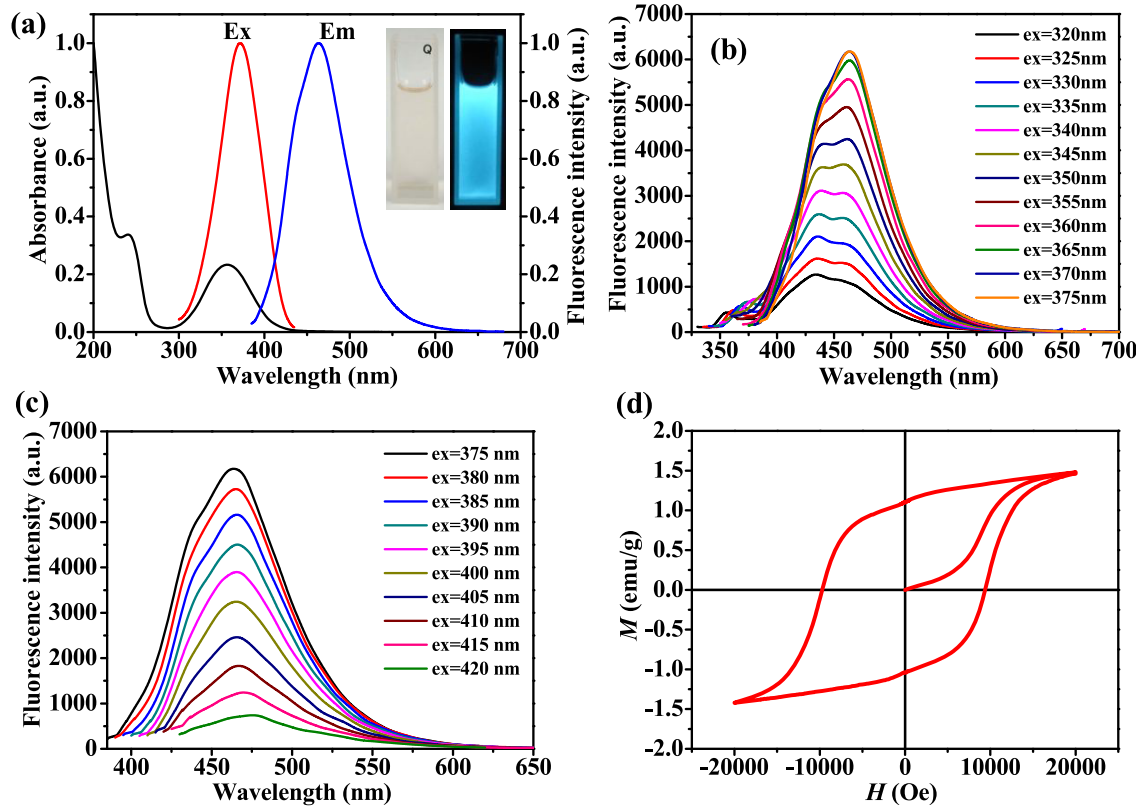

(d)

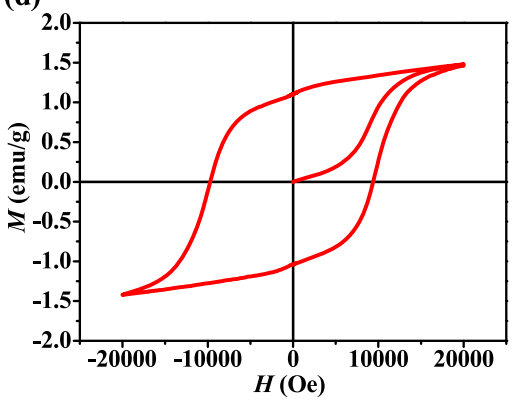

Figure 3. (a) UV-vis absorption spectrum and excitation spectrum $\left(\lambda_{\mathrm{em}}=465 \mathrm{~nm}\right)$ and emission spectrum $\left(\lambda_{\mathrm{ex}}=375 \mathrm{~nm}\right)$ of N,Co-CDs. Insert: Photograph of N,Co-CDs under the excitation of white light (left) and UV lamp with a $365 \mathrm{~nm}$ (right) wavelength. (b, c) Fluorescence spectra of $\mathrm{N}, \mathrm{Co}-\mathrm{CD}$ s with the excitation wavelength increasing from 320 to $420 \mathrm{~nm}$. (d) $M-H$ behavior of N,Co-CDs.

wavelength-dependent feature of these N,Co-CDs. ${ }^{41}$ The maximum excitation wavelength and emission wavelength of $\mathrm{N}, \mathrm{Co}-\mathrm{CDs}$ are 375 and $465 \mathrm{~nm}$, respectively. By using the integrating sphere, the absolute fluorescent quantum yield of $\mathrm{N}$,Co-CDs appearing at $465 \mathrm{~nm}$ upon a $375 \mathrm{~nm}$ excitation is calculated to be $71.91 \%$, which is much higher than that of some reported doped CDs. ${ }^{13,15}$

The time-resolved fluorescence spectrum of N,Co-CDs was recorded, and the fluorescent lifetime of N,Co-CDs was measured according to time-correlated single-photo counting system. The fluorescent decay traces are well-fitted by the following double-exponential equation

$$
\langle\tau\rangle=\left(\sum b_{i} \tau_{i}^{2}\right) /\left(\sum b_{i} \tau_{i}\right)
$$

Herein, $\tau_{i}$ is the fluorescent lifetime of N,Co-CDs and $b_{i}$ is the normalized pre-exponential factor, respectively. It is clearly shown in the insert table of Figure S2 that N,Co-CDs exhibit two fluorescence decay components: $\tau_{1}\left(b_{i}\right)$ of $7.39 \mathrm{~ns}$ $(17.83 \%)$ and $\tau_{2}\left(b_{2}\right)$ of $13.76 \mathrm{~ns}(82.17 \%)$, respectively. The average fluorescent lifetime of N,Co-CDs is about 13.10 ns (excited at $340 \mathrm{~nm}$ ) (insert table of Figure S2) that is much longer than that of some reported doped CDs. ${ }^{13,15,42}$ As further presented in Figures S3-S5, the fluorescence intensity of N,Co-CDs remains unchanged obviously under long time UV light irradiation (180 min) or in buffer solution with a wide $\mathrm{pH}$ value $(3.0-11.0)$ and extremely high $\mathrm{NaCl}$ concentration $(3.0 \mathrm{M})$. The fluorescence of N,Co-CDs remains almost constant even after 1 month storage at room temperature. The excellent photochemical stability of N,CoCDs under extremely harsh environment conditions and long time storage promotes their further application in biological analysis and live cell imaging.

Due to the doping of Co element, the as-prepared N,CoCDs may possess magnetic property. ${ }^{8}$ The magnetic property of N,Co-CDs was measured at room temperature, and the field-dependent magnetization $(M-H)$ curve is shown in Figure $3 \mathrm{~d}$. The magnetic hysteresis loop in the $M-H$ curve of
N,Co-CDs shows that the these N,Co-CDs exhibit a ferromagnetic behavior with a saturated magnetization $\left(M_{\mathrm{s}}\right)$ value of $1.476 \mathrm{emu} / \mathrm{g}$ and a coercive force $\left(H_{\mathrm{c}}\right)$ of $9.68 \times 10^{3}$ Oe. Compared with other transition-metal ion-doped CDs and some hybrid CD nanoconstucts, ${ }^{8,11,12}$ the $M_{s}$ value of N,Co$\mathrm{CDs}$ is much smaller, implying the relatively low magnetic property of these N,Co-CDs. The ferromagnetism behavior of $\mathrm{N}, \mathrm{Co}-\mathrm{CDs}$ is only attributed to the unpaired electrons and the magnetization of the doped Co element. The extra low content of Co (8.06 wt \%) in these N,Co-CDs may result in the weak ferromagnetic behavior of N,Co-CDs. Meanwhile, the spin canting effect in $\mathrm{Co}$ atom surface results in the reduced magnetization of N,Co-CDs. For these N,Co-CDs with smaller sizes, the magnetization is inclined to decrease at room temperature after long time storage. Although numerous paramagnetic and super-paramagnetic CDs are suitable for the magnetic resonance imaging, the ferromagnetic property of $\mathrm{N}, \mathrm{Co}-\mathrm{CD}$ s makes them potentially applicable for trapping and extracting pathogenic bacteria and cancer cells in complicated sample matrixes.

Cyclic voltammograms (CVs) were recorded to calculate the highest occupied molecular orbital (HOMO) and the lowest unoccupied molecular orbital (LUMO) energy levels of N,Co$\mathrm{CDs}$ and N-CDs. CVs were carried out in tetrabutylammonium hexafluorophosphate solution by using the standard three-electrode system: working electrode of CDs or N,CoCDs coated glassy carbon electrode, counter electrode of platinum wire electrode, and reference electrode of $\mathrm{Ag} / \mathrm{AgCl}$ electrode, respectively. ${ }^{43} \mathrm{HOMO}$ and LUMO energy levels in electronvolt as well as the electrochemical energy gap $\left(E_{\mathrm{g}}\right.$ in electronvolt) of these CDs can be calculated according to the following equations ${ }^{43,44}$

$$
\begin{aligned}
E_{(\mathrm{HOMO})} & =-\mathrm{e}\left(E_{\mathrm{ox}}+4.4\right)(\mathrm{eV}) \text { and } E_{(\mathrm{LUMO})} \\
& =-\mathrm{e}\left(E_{\mathrm{red}}+4.4\right)(\mathrm{eV})
\end{aligned}
$$



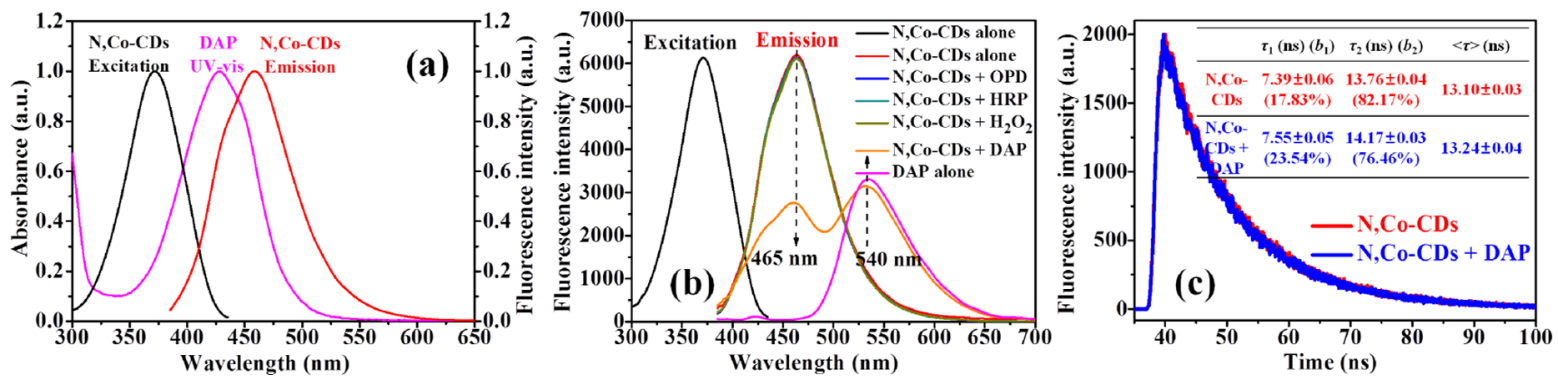

Figure 4. (a) UV-vis absorption spectrum of DAP; excitation and emission spectra of N,Co-CDs. (b) Excitation spectrum of N,Co-CDs alone and emission spectra of N,Co-CDs alone $(100 \mu \mathrm{g} / \mathrm{mL}), \mathrm{N}, \mathrm{Co}-\mathrm{CDs}+\mathrm{OPD}(5 \mathrm{mM}), \mathrm{N}, \mathrm{Co}-\mathrm{CDs}+\mathrm{HRP}(10 \mu \mathrm{g} / \mathrm{mL}), \mathrm{N}, \mathrm{Co}-\mathrm{CDs}+\mathrm{H}_{2} \mathrm{O}_{2}(500 \mu \mathrm{M})$, N,Co-CDs + DAP $(100 \mu \mathrm{M})$, and DAP alone $(100 \mu \mathrm{M})$. (c) Fluorescence decay traces of N,Co-CDs before and after the addition of DAP. The test was made at the emission wavelength of $465 \mathrm{~nm} . \tau$ is the fluorescent lifetime of N,Co-CDs, and $b$ is the normalized pre-exponential factor.

Herein, $E_{\mathrm{ox}}$ and $E_{\mathrm{red}}$ represent the oxidation and reduction potentials, respectively. It is clear from Figure $S 6$ that the $E_{\text {red }}$ values are determined to be $-0.4064 \mathrm{~V}$ for $\mathrm{N}, \mathrm{Co}-\mathrm{CDs}$ and $-0.4027 \mathrm{~V}$ for $\mathrm{N}-\mathrm{CD}$, respectively. Therefore, the LUMO energy levels are around $-3.99 \mathrm{eV}$ for $\mathrm{N}, \mathrm{Co}-\mathrm{CDs}$ and -4.00 $\mathrm{eV}$ for N-CDs. Due to the irreversible oxidation behavior, the HOMO energy levels can be calculated indirectly by the following equations ${ }^{44}$

$$
E_{(\mathrm{HOMO})}=E_{(\mathrm{LUMO})}-E_{\mathrm{g}}(\mathrm{eV})
$$

The optical energy band gap $\left(E_{\mathrm{g}}\right)$ is the absorption edge of the absorption peak (357 nm) of CDs in the UV-vis spectrum, and $E_{\mathrm{g}}$ is estimated to be $3.61 \mathrm{eV}$. So, the HOMO energy levels are $-7.60 \mathrm{eV}$ for $\mathrm{N}, \mathrm{Co}-\mathrm{CDs}$ and $-7.61 \mathrm{eV}$ for $\mathrm{N}-\mathrm{CD}$. As shown in Figure S7, both the HOMO and the LUMO energy levels of $\mathrm{N}-\mathrm{CD}$ are approximately equal to those of $\mathrm{N}, \mathrm{Co}-$ CDs; thus, the spectral properties of CDs remain almost unchanged before or after the doping of metal Co element (Figures S8 and S9).

2.3. Fluorescence Detection Mechanism. In this assay, a novel fluorescent magnetic N,Co-CD-based ratiometric fluorescent probe for the detection of cholesterol and uric acid, which responded to enzyme-catalyzed $\mathrm{H}_{2} \mathrm{O}_{2}$-generation reaction, was developed. As shown in Scheme 1, CA, $\mathrm{CoCl}_{2}$. $6 \mathrm{H}_{2} \mathrm{O}$, and DETA are used to prepare N,Co-CDs with emission wavelength of $465 \mathrm{~nm}$ by one-pot hydrothermal method. $\mathrm{H}_{2} \mathrm{O}_{2}$, which is the product in the oxidation reactions of cholesterol and uric acid with $\mathrm{O}_{2}$ under the catalysis of their specific oxidoreductases (cholesterol oxidase and urate oxidase), can oxidize OPD to produce DAP with the catalysis of HRP. DAP with emission wavelength of $540 \mathrm{~nm}$ can quench the fluorescence of several carbon-based fluorescence nanomaterials through IFE. ${ }^{15,29}$ Therefore, such N,Co-CDs with excellent properties can be used as the powerful ratiometric fluorescent probes for indirect detection of cholesterol and uric acid.

The possible fluorescence quenching mechanism in N,CoCDs/DAP system may be probably IFE. ${ }^{45}$ As seen in Figure 4a, DAP shows a strong UV-vis absorption peak located at $430 \mathrm{~nm}$ and the absorption spectrum of DAP can partially overlay with the emission spectrum of N,Co-CDs. Our preliminary results showed that the molar absorption coefficients of DAP at 375 and $465 \mathrm{~nm}$ were about $6.36 \times$ $10^{3} \mathrm{~L} /(\mathrm{mol} \mathrm{cm})$ and $9.01 \times 10^{3} \mathrm{~L} /(\mathrm{mol} \mathrm{cm})$ whereas OPD exhibits almost no absorbance at both 375 and $465 \mathrm{~nm}$. These results suggest the strong absorption ability of DAP and the weak absorption ability of OPD at these two wavelengths. As a consequence, DAP with strong UV-vis absorption ability can absorb both the excitation light and the emission light of $\mathrm{N}, \mathrm{Co}-\mathrm{CD}$ s wereas OPD may not affect the emission light of N,Co-CDs at all. As indicated in Figures $4 \mathrm{~b}$ andS10, N,CoCDs show metal ion, amino acid, and carbohydrate insensitivity. Obviously, other materials (OPD and HRP) during the enzyme-catalyzed DAP-generation reaction exhibit no influences on the fluorescence of N,Co-CDs. Thus, these $\mathrm{N}, \mathrm{Co}-\mathrm{CD}$ s are efficient fluorescence donor agents in $\mathrm{N}, \mathrm{Co}-$ CDs/DAP system based on IFE.

To further understand the detailed fluorescence quenching mechanism of N,Co-CDs/DAP system, the fluorescent lifetimes of N,Co-CDs without DAP were recorded and the results were displayed in Figure 4c. As exhibited in the insert table of Figure $4 c$, the corresponding average fluorescent lifetime of $\mathrm{N}, \mathrm{Co}-\mathrm{CDs}$ with $\mathrm{DAP}$ is about $13.24 \mathrm{~ns}$. The fluorescent lifetime of $\mathrm{N}, \mathrm{Co}-\mathrm{CDs}$ remains almost constant, illustrating that there is no significant electron or energy transfer process in N,Co-CDs/DAP system. ${ }^{46}$ The $\zeta$ potentials of N,Co-CDs, DAP, and N,Co-CDs/DAP system are all positive (Figure S11), so the nonignorable electrostatic repulsive force between $\mathrm{N}, \mathrm{Co}-\mathrm{CDs}$ and DAP exists. The distance between N,Co-CDs and DAP is hardly shorter than $10 \mathrm{~nm}$; thus, the Förster resonance energy transfer (FRET) cannot occur in this system. ${ }^{47}$ All results suggest that the fluorescence quenching mechanism in N,Co-CDs/DAP system is attributed to IFE rather than photoinduced electron transfer or Förster resonance energy transfer (FRET).

2.4. Fluorescence Detection of Cholesterol and Uric Acid. These fluorescent magnetic N,Co-CDs are used as fluorescent nanoprobes for the indirect determinations of cholesterol and uric acid through enzyme-catalyzed $\mathrm{H}_{2} \mathrm{O}_{2}$ generation reaction. Before detection, several important analytical parameters need to be optimized previously: (a) amount of N,Co-CDs, (b) concentration of OPD, (c) amount of HRP, (d) $\mathrm{pH}$ value of phosphate buffer $(3.15 \mathrm{mM}$ $\mathrm{Na}_{2} \mathrm{HPO}_{4}$ and $6.85 \mathrm{mM} \mathrm{NaH} \mathrm{PO}_{4}$ ), (e) incubation temperature, (f) reaction time, $(\mathrm{g})$ amount of cholesterol oxidase, and (h) amount of urate oxidase. Fluorescence intensity of N,CoCDs at $465 \mathrm{~nm}\left(I_{465}\right)$ and that of DAP at $540 \mathrm{~nm}\left(I_{540}\right)$ were recorded. According to the ratiometric fluorescence signal $I_{540} /$ $I_{465}$ shown in Figures S12-S14, the following optimal analytical parameters are found to obtain the best result: (a) $100 \mu \mathrm{g} / \mathrm{mL}$ N,Co-CDs, (b) $5 \mathrm{mM}$ OPD, (c) $10 \mu \mathrm{g} / \mathrm{mL}$ HRP, (d) $\mathrm{pH} 6.5$ of phosphate buffer, (e) incubation temperature of $37^{\circ} \mathrm{C}$, (f) reaction time of $25 \mathrm{~min},(\mathrm{~g}) 0.05 \mathrm{U} / \mathrm{mL}$ cholesterol oxidase, and $(\mathrm{h}) 0.06 \mathrm{U} / \mathrm{mL}$ urate oxidase. 

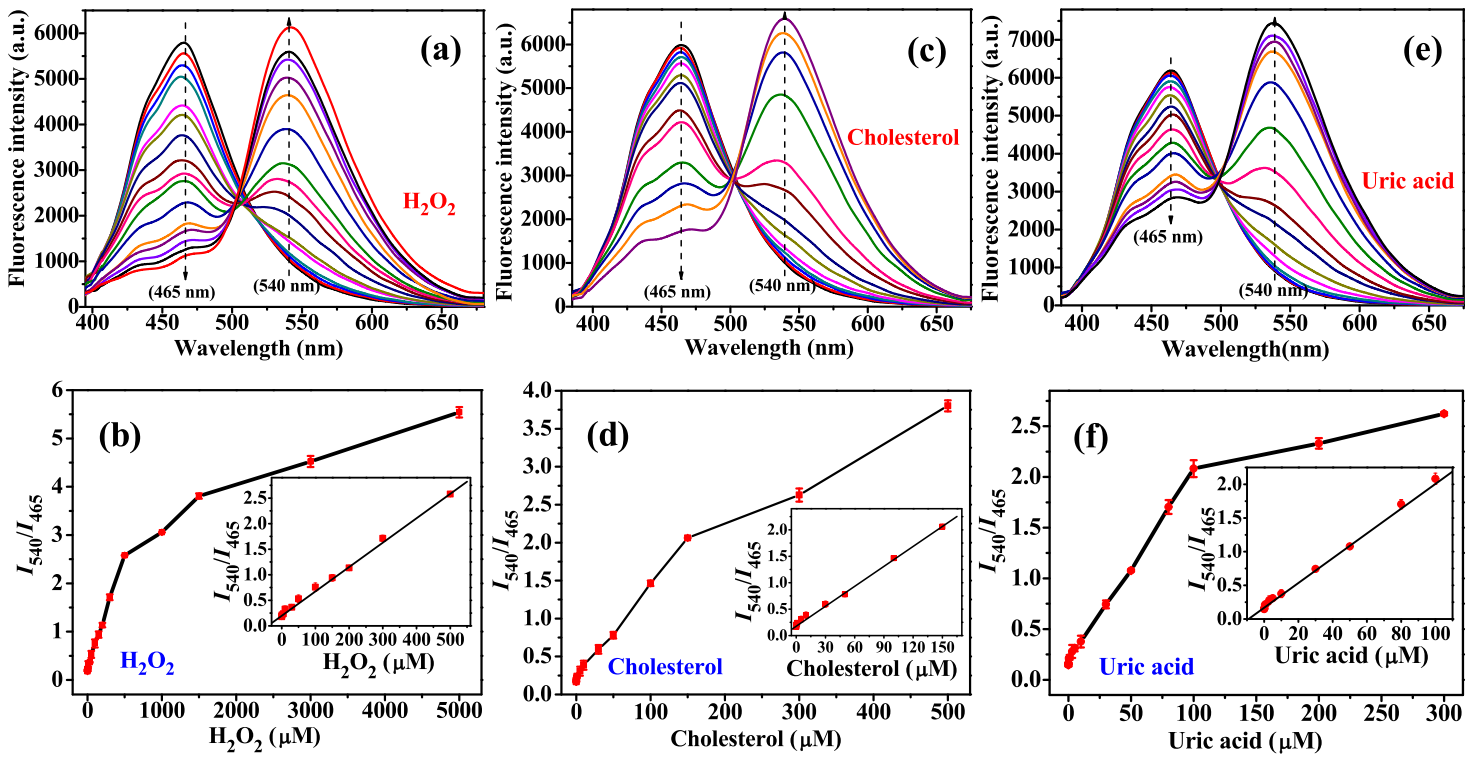

Figure 5. Fluorescence spectra of this ratiometric fluorescent probe with increasing concentrations of $\mathrm{H}_{2} \mathrm{O}_{2}$ (a), cholesterol (c), and uric acid (e). (b) The curve of $I_{540} / I_{465}$ value versus the $\mathrm{H}_{2} \mathrm{O}_{2}$ concentration in the range 0.01-5000 $\mu \mathrm{M}$; insert: calibration curve of $\mathrm{H}_{2} \mathrm{O}_{2}$ detection in the range 0.01-500 $\mu \mathrm{M}$. (d) The curve of $I_{540} / I_{465}$ value versus the cholesterol concentration in the range $0.01-500 \mu \mathrm{M}$. Insert: Calibration curve of cholesterol detection in the range $0.01-150 \mu \mathrm{M}$. (f) The curve of $I_{540} / I_{465}$ value versus the uric acid concentration in the range $0.01-300 \mu \mathrm{M}$. Insert: calibration curve of uric acid detection in the range $0.01-100 \mu \mathrm{M}$.
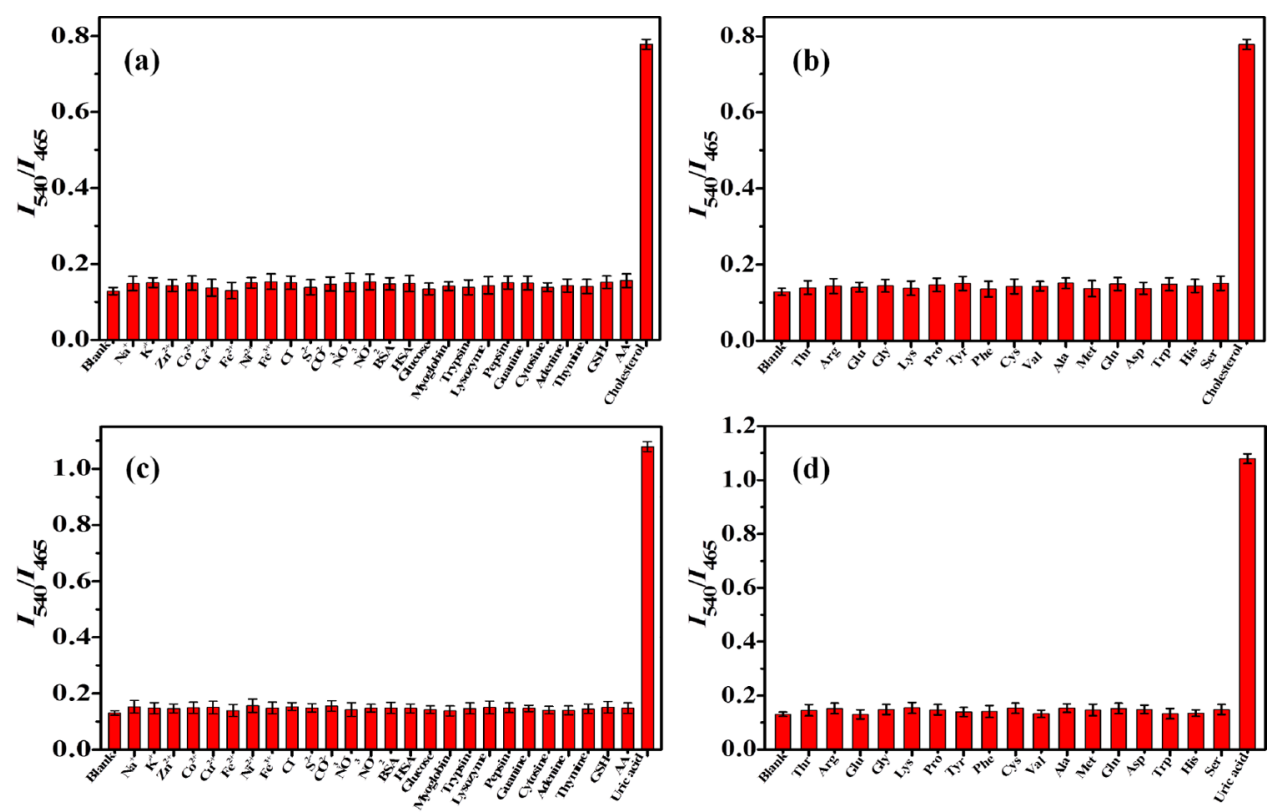

Figure 6. Ratiometric fluorescence signal $I_{540} / I_{465}$ with various concentrations of different interferences for the detections of cholesterol (a, b) and uric acid (c, d). The concentrations of cholesterol and uric acid were $50 \mu \mathrm{M}$, and the concentrations of other interferences were all $100 \mu \mathrm{M}$.

Under the optimized analytical parameters (Figure S12), the fluorescence spectra of the sensing platform were measured in the presence of $\mathrm{H}_{2} \mathrm{O}_{2}$ with the concentration range of $0.01 \mu \mathrm{M}$ to $5 \mathrm{mM}$. As shown in Figure $5 \mathrm{a}$, the $I_{465}$ value decreases gradually whereas the $I_{540}$ value increases correspondingly with the increasing concentration of $\mathrm{H}_{2} \mathrm{O}_{2}$ and the ratiometric fluorescence signal $I_{540} / I_{465}$ increases accordingly (Figure $5 \mathrm{~b}$ ). As indicated in the insert of Figure $5 \mathrm{~b}$, when the concentration of $\mathrm{H}_{2} \mathrm{O}_{2}$ increases from 0.01 to $500 \mu \mathrm{M}$, a good linear relationship exists between the $I_{540} / I_{465}$ value and the concentration of $\mathrm{H}_{2} \mathrm{O}_{2}$ with the linear equation $I_{540} / I_{465}=$ $0.00477\left[\mathrm{H}_{2} \mathrm{O}_{2}\right](\mu \mathrm{M})+0.1973(n=3$, correlation coefficient of 0.9982 ). The detection limit (LOD) of $\mathrm{H}_{2} \mathrm{O}_{2}$ is calculated to be $6.9 \mathrm{nM}$ based on $3 \sigma / \mathrm{K}$ ( $\sigma$ is the standard deviation of blank measurement, and $K$ is the slope of the calibration graph), which is better than some existing fluorescence probes for $\mathrm{H}_{2} \mathrm{O}_{2} \cdot{ }^{15,30}$ Such a fluorescent magnetic N,Co-CD-based ratiometric fluorescent probe exhibits ultrasensitive detection of $\mathrm{H}_{2} \mathrm{O}_{2}$, implying that this method can be used to detect cholesterol and uric acid indirectly.

2.4.1. Sensitivity of Cholesterol and Uric Acid Detection. This fluorescent magnetic N,Co-CD-based ratiometric fluorescence sensing platform was used for the detection of cholesterol. Under the optimized conditions (Figures S12 and 
S13), the fluorescence spectra of this sensing platform were recorded after adding increasing concentration of cholesterol from 0.01 to $500 \mu \mathrm{M}$. It is shown that the $I_{465}$ value decreases whereas the $I_{540}$ value increases gradually with the increasing concentration of cholesterol (Figure 5c). The ratiometric fluorescence signal $I_{540} / I_{465}$ increases according to the increment of the concentration of cholesterol (Figure $5 \mathrm{~d}$ ). As further shown in the insert of Figure $5 \mathrm{~d}$, the ratiometric fluorescence signal $I_{540} / I_{465}$ exhibits a good linear relationship to the cholesterol concentration in the range $0.01-150 \mu \mathrm{M}$. The linear fitting equation is $I_{540} / I_{465}=0.01258$ [cholesterol] $(\mu \mathrm{M})+0.1767(n=3$, correlation coefficient of 0.9975$)$, and the LOD of cholesterol is $3.6 \mathrm{nM}$ based on $3 \sigma / K$.

This fluorescent magnetic N,Co-CD-based ratiometric fluorescent sensing platform was continuously used to detect uric acid. Under optimized conditions (Figures S12 and S14), the fluorescence spectra of this sensing platform were recorded after the addition of increasing concentration of uric acid from 0.01 to $300 \mu \mathrm{M}$. It is obvious that the $I_{465}$ value decreases whereas the $I_{540}$ value increases gradually with the increasing concentration of uric acid (Figure 5e). As shown in Figure 5f, the ratiometric fluorescence signal $I_{540} / I_{465}$ increases with the increment of the concentration of uric acid. Furthermore, the ratiometric fluorescence signal $I_{540} / I_{465}$ shows a linear relationship with the uric acid concentration in the range of $0.01-100 \mu \mathrm{M}$ (insert of Figure 5f). The fitted linear equation is $I_{540} / I_{465}=0.01838$ [uric acid] $(\mu \mathrm{M})+0.1672(n=3$, correlation coefficient of 0.9984$)$, and the LOD of uric acid is $3.4 \mathrm{nM}$ based on $3 \sigma / K$.

Comparing with other reported colorimetry, fluorescence spectrometry, chemiluminescence, and electrochemical methods by using other nanomaterials, our method exhibits ultrawider linear ranges and relatively lower detection limits for the detections of cholesterol and uric acid. As shown in Tables S2 and S3, such N,Co-CD-based ratiometric fluorescence sensing platform shows comparable or even superior sensitivity for the determination of cholesterol and uric acid. Most importantly, these fluorescent magnetic N,Co-CDs possessing magnetic property are expediently separated from the detection system by using the magnet, which makes them reusable during this detection strategy.

2.4.2. Selectivity and Practicability Investigations. To investigate the selectivity of this ratiometric fluorescence universal platform for the detection of cholesterol and uric acid, the interferences of common ions, amino acids, carbohydrates, nucleotides, and proteins on the ratiometric fluorescence signal $I_{540} / I_{465}$ were studied. As shown in Figure 6 , when the concentrations of cholesterol and uric acid are 50 $\mu \mathrm{M}$ whereas all of the concentrations of other interferences are $100 \mu \mathrm{M}$, these interferences have no significant influences on the ratiometric fluorescence measurement. Although these $\mathrm{N}, \mathrm{Co}-\mathrm{CD}$ are sensitive toward $\mathrm{Ag}^{+}$and $\mathrm{Fe}^{3+}$ (Figure S10), the interference of $\mathrm{Ag}^{+}$on the detection system can be omitted due to the generation of $\mathrm{Ag}_{3} \mathrm{PO}_{4}$ precipitate in the phosphate buffer. This sensing platform is also insensitive toward $\mathrm{Fe}^{3+}$, which ascribes to the negligible background signal of such a ratiometric fluorescence strategy by using the ratiometric fluorescence signal $I_{540} / I_{465}$ as the detection signal.

Due to the ultrahigh specificity of the enzyme-substance reactions, the as-prepared sensing strategy exhibits excellent selectivity for cholesterol and uric acid determinations. In the proposed sensing method, enzyme-catalyzed $\mathrm{H}_{2} \mathrm{O}_{2}$-generation reaction is the most important section for detection of signal transformation. But in real human blood serum samples, the endogenous substances (ascorbic acid, L-cysteine, and glutathione) can reduce and consume the produced $\mathrm{H}_{2} \mathrm{O}_{2}$ to affect the detection results, which is vital to the whole strategy. However, when these endogenous substances coexist in cholesterol and uric acid, the ratiometric fluorescence signal $I_{540} / I_{465}$ remains almost constant (Figure S15). Since the amounts of ascorbic acid, L-cysteine, and glutathione in real human blood serum samples are much lower than those of cholesterol and uric acid, the influences of these interferences can be omitted. These results confirm the good specificity and the potential biological application of this ratiometric fluorescence sensing approach for cholesterol and uric acid in real human blood serum samples.

The practicability of this ratiometric fluorescence universal platform was investigated through detecting cholesterol and uric acid in human blood serum by using the standard addition approach. As shown in Table S4, the amounts of cholesterol found in these human blood serum are in accordance with the reported values $(2.86-5.98 \mathrm{mM}) .^{48}$ As indicated in Table S5, the amounts of uric acid found in human blood serum are in accordance with the reported values $(0.12-0.46 \mathrm{mM}) .{ }^{19}$ The recoveries for cholesterol with three different concentrations $(5,50$, and $100 \mu \mathrm{M})$ in human serum samples increase from 95.8 to $103.6 \%$, and the relative standard deviations are all lower than $1.3 \%$ for three replicate measurements. The recoveries for uric acid with three different concentrations $(0.5,5$, and $50 \mu \mathrm{M})$ in human serum samples increase from 98.6 to $103.7 \%$, and the relative standard deviations are all lower than $1.1 \%$ for three replicate measurements. Therefore, this strategy is a promising design for the detections of cholesterol and uric acid in real samples. All of the results prove the good selectivity and the super practicability of such $\mathrm{N}, \mathrm{Co}-\mathrm{CD}$-based fluorescent probes for biomarker detections in real biological samples.

\section{CONCLUSIONS}

In summary, $\mathrm{N}, \mathrm{Co}-\mathrm{CDs}$ were prepared through a simple and convenient one-pot hydrothermal technique by using $\mathrm{CA}$, $\mathrm{CoCl}_{2} \cdot 6 \mathrm{H}_{2} \mathrm{O}$, and DETA as precursors. Due to the co-doping of nonmetal $\mathrm{N}$ element and metal Co element, N,Co-CDs showed excellent photochemical properties and ferromagnetic property. On the basis of the IFE process in N,Co-CDs/DAP system, a N,Co-CDs-based ratiometric fluorescent probe was established for the determination of cholesterol and uric acid indirectly. The detection limits of cholesterol and uric acid were 3.6 and $3.4 \mathrm{nM}$, respectively, which met the requirements for the highly sensitive monitoring of low levels of cholesterol and uric acid in human blood serum. The proposed N,Co-CDbased probing platform is a desirable approach for biomarker monitoring in disease diagnosis and clinical therapy.

\section{EXPERIMENTAL SECTION}

4.1. Reagents and Materials. CA, $\mathrm{CoCl}_{2} \cdot 6 \mathrm{H}_{2} \mathrm{O}$, DETA, OPD, HRP, uric acid, cholesterol, and cholesterol esterase were obtained from Aladdin Chemical Co., Ltd. (Shanghai, China). DAP, cholesterol oxidase, urate oxidase, amino acids, and all other biological substances were obtained from SigmaAldrich Co., Ltd. (St. Louis, MO). All chemical reagents were purchased from Sinopharm Chemical Reagent Co., Ltd. (Shanghai, China). All reagents were of the highest commercially available purity and used directly as received. 
Ultrapure water with resistivity of $18.2 \mathrm{M} \Omega \mathrm{cm}$ was prepared through Millipore-Q Academic purification system (Bedford).

4.2. Synthesis of N,Co-CDs, and N-CDs. The fluorescent property of N,Co-CDs can be affected by the amount of CA, the volume of DETA, the amount of $\mathrm{CoCl}_{2} \cdot 6 \mathrm{H}_{2} \mathrm{O}$, the reaction temperature, and the reaction time. As shown in Figure S16, the optimal conditions for synthesis of $\mathrm{N}, \mathrm{Co}-\mathrm{CDs}$ were as follows: $2.0 \mathrm{~g}$ of CA, $0.07 \mathrm{~mL}$ of DETA, $0.4 \mathrm{~g}$ of $\mathrm{CoCl}_{2} \cdot 6 \mathrm{H}_{2} \mathrm{O}$, $160{ }^{\circ} \mathrm{C}$, and $8 \mathrm{~h}$. Therefore, for the synthesis of N,Co-CDs, 2.0 $\mathrm{g}$ of CA and $0.4 \mathrm{~g}$ of $\mathrm{CoCl}_{2} \cdot 6 \mathrm{H}_{2} \mathrm{O}$ were first dissolved in $20 \mathrm{~mL}$ of ultrapure water and then $0.07 \mathrm{~mL}$ of DETA was added into the above solution. The solution was dissolved completely by an ultrasonic method for $10 \mathrm{~min}$. Thereafter, the solution was transferred into a $50 \mathrm{~mL}$ Teflon-lined stainless steel autoclave chamber and reacted at $160{ }^{\circ} \mathrm{C}$ for $8 \mathrm{~h}$. After natural cooling to room temperature, the solution was collected and dialyzed in a dialysis bag with a cutoff molecular weight of $500 \mathrm{Da}$ for $72 \mathrm{~h}$. Finally, the outside solution was collected and concentrated to be about $100 \mathrm{~mL}$ under rotary evaporation. The solid powder of N,Co-CDs was finally obtained via vacuum freeze-drying for $48 \mathrm{~h}$. This N,Co-CD powder was stored at $4{ }^{\circ} \mathrm{C}$ for further applications. The synthesis and purification processes of $\mathrm{N}$ $\mathrm{CDs}$ are all same as above just without the addition of $\mathrm{CoCl}_{2}$. $6 \mathrm{H}_{2} \mathrm{O}$.

4.3. Characterizations of $\mathrm{N}, \mathrm{Co}-\mathrm{CDs}$ and $\mathrm{N}-\mathrm{CD}$. TEM and HRTEM images were taken with a JEM-2100F highresolution transmission emission microscope (JEOL, Japan). XRD spectrum was measured on a Bruker D-8 Advance Powder X-ray diffractometer (Bruker, Germany). XPS spectra were taken with ESCALAB 250Xi X-ray photoelectron spectroscopy (Thermo Fisher Scientific). FT-IR spectrum was recorded on a Thermo Nicolet iS10 spectrometer (Thermo Fisher Scientific). Elemental analysis was carried out on a Vario EL/Micro Cube organic element analyzer (Elementar Analysensysteme $\mathrm{GmbH}$, Germany). Magnetic property was recorded by using a VersaLab Vibration Sample Magnetometer (Quantum Design). UV-vis absorption spectra were recorded on a Shimadzu UV-3600 Plus UV-vis-NIR spectrophotometer (Shimadzu, Japan). Fluorescence spectra were recorded on a Thermo Scientific Lumina fluorescence spectrometer (Thermo Fisher Scientific). Time-resolved fluorescence spectra were measured on a Horiba Scientific QM-8075 high sensitivity steady-state transient fluorescence spectrometer (HORIBA, Japan). $\zeta$-Potential was recorded on a Zetasizer Nano ZS (Malvern, U.K.). CV curves were obtained from a Chenhua CHI-760E electrochemical workstation (Shanghai, China). The $\mathrm{pH}$ values were mediated using a Sartorius PB-10 pH meter (Sartorius, China).

4.4. Fluorescent Sensing of Cholesterol and Uric Acid. For $\mathrm{H}_{2} \mathrm{O}_{2}$ detection, $500 \mu \mathrm{L}$ of $30 \mathrm{mM}$ OPD, $30 \mu \mathrm{L}$ of 1 $\mathrm{mg} / \mathrm{mL} \mathrm{HRP}$, and $70 \mu \mathrm{L}$ of different concentrations of $\mathrm{H}_{2} \mathrm{O}_{2}$ were mixed in $10 \mathrm{mM}$ phosphate buffer $(\mathrm{pH}=6.5)$. The solution was stored in the dark and incubated at $37{ }^{\circ} \mathrm{C}$ for 25 min. Then, $100 \mu \mathrm{L}$ of $\mathrm{N}, \mathrm{Co}-\mathrm{CD}$ solution $(3 \mathrm{mg} / \mathrm{mL})$ was added into the mixture and the solution was finally diluted to 3 $\mathrm{mL}$ with $10 \mathrm{mM}$ phosphate buffer $(\mathrm{pH}=6.5)$. After additional incubation at $25{ }^{\circ} \mathrm{C}$ for $1 \mathrm{~min}$, the fluorescence spectra were recorded under the excitation wavelength of $375 \mathrm{~nm}$ and the ratiometric fluorescence signal $I_{540} / I_{465}$ was used to detect $\mathrm{H}_{2} \mathrm{O}_{2}$.

For the fluorescent sensing of cholesterol and uric acid, 500 $\mu \mathrm{L}$ of $30 \mathrm{mM}$ OPD, $30 \mu \mathrm{L}$ of $1 \mathrm{mg} / \mathrm{mL} \mathrm{HRP,} 100 \mu \mathrm{L}$ of different concentrations of cholesterol or uric acid, and $50 \mu \mathrm{L}$ of $3 \mathrm{U} / \mathrm{mL}$ cholesterol oxidase for cholesterol or $60 \mu \mathrm{L}$ of $3 \mathrm{U} /$ $\mathrm{mL}$ urate oxidase for uric acid were mixed thoroughly in 10 $\mathrm{mM}$ phosphate buffer $(\mathrm{pH}=6.5)$. The solution was stored in the dark and incubated at $37{ }^{\circ} \mathrm{C}$ for $25 \mathrm{~min}$. Then, $100 \mu \mathrm{L}$ of $\mathrm{N}$,Co-CD solution $(3 \mathrm{mg} / \mathrm{mL})$ was added into the mixture. The solution was finally diluted to $3 \mathrm{~mL}$ with $10 \mathrm{mM}$ phosphate buffer $(\mathrm{pH}=6.5)$. After additional incubation at 25 ${ }^{\circ} \mathrm{C}$ for $1 \mathrm{~min}$, the fluorescence spectra were recorded under the excitation wavelength of $375 \mathrm{~nm}$. The ratiometric fluorescence signal $I_{540} / I_{465}$ was utilized for the determination of cholesterol and uric acid.

For cholesterol detection in human blood serum, $500 \mu \mathrm{L}$ of a human blood serum sample was mixed with $10 \mu \mathrm{L}$ of $1 \mathrm{mg} /$ $\mathrm{mL}$ cholesterol esterase to hydrolyze cholesterol ester to produce free cholesterol and then diluted by 100 times by adding $10 \mathrm{mM}$ phosphate buffer $(\mathrm{pH}=6.5)$. For uric acid detection in human blood serum, the human blood serum sample was diluted by 100 times by adding $10 \mathrm{mM}$ phosphate buffer $(\mathrm{pH}=6.5)$. The diluted human blood serum replaced with standard samples was measured as described above.

\section{ASSOCIATED CONTENT}

\section{S Supporting Information}

The Supporting Information is available free of charge on the ACS Publications website at DOI: 10.1021/acsomega.9b00874.

CIE color profile; fluorescence decay trace; effects of irradiation time; $\mathrm{pH}$ value, and ionic strength on fluorescence; CV curves, energy levels; UV-vis and fluorescence spectra; influences of interferences; $\zeta$ potential data; influences of parameters for detection; influences of parameters for synthesis; elemental analysis; comparison tables; and real sample detection (PDF)

\section{AUTHOR INFORMATION}

\section{Corresponding Author}

*E-mail: qi.xiao@whu.edu.cn. Tel/Fax: +86 7713908065.

ORCID

Shan Huang: 0000-0002-6133-1853

Yue Zhang: 0000-0002-6140-3757

\section{Notes}

The authors declare no competing financial interest.

\section{ACKNOWLEDGMENTS}

This work was financially supported by the National Natural Science Foundation of China (21864006, 21763005, and 21563006), Natural Science Foundation of Guangxi Province (2017GXNSFDA198034, 2017GXNSFFA198005, and 2016GXNSFBA380118), Guangxi Scientific and Technological Development Projects (AD17195081), China Scholarship Council Project (201708455047), the High-Level-Innovation Team (guijiaoren[2017]38) and Outstanding Scholar Project of Guangxi Higher Education Institutes, and BAGUI Scholar Program of Guangxi Province of China.

\section{REFERENCES}

(1) Yan, F. Y.; Jiang, Y. X.; Sun, X. D.; Bai, Z. J.; Zhang, Y.; Zhou, X. G. Surface modification and chemical functionalization of carbon dots: A review. Microchim. Acta 2018, 185, 424.

(2) Wang, H.; Chen, Q. W.; Zhou, S. Q. Carbon-based hybrid nanogels: A synergistic nanoplatform for combined biosensing, 
bioimaging, and responsive drug delivery. Chem. Soc. Rev. 2018, 47, 4198-4232.

(3) Xu, Q.; Kuang, T. R.; Liu, Y.; Cai, L. L.; Peng, X. F.; Sreeprasad, T. S.; Zhao, P.; Yu, Z. Q.; Li, N. Heteroatom-doped carbon dots: Synthesis, characterization, properties, photoluminescence mechanism and biological applications. J. Mater. Chem. B 2016, 4, 72047219.

(4) Xu, Q.; Liu, Y.; Su, R. G.; Cai, L. L.; Li, B. F.; Zhang, Y. Y.; Zhang, L. Z.; Wang, Y. J.; Wang, Y.; Li, N.; Gong, X.; Gu, Z. P.; Sreeprasad, T. S.; et al. Highly fluorescent Zn-doped carbon dots as Fenton reaction-based bio-sensors: an integrative experimentaltheoretical consideration. Nanoscale 2016, 8, 17919-17927.

(5) Meng, A.; Xu, Q. H.; Zhao, K.; Li, Z. J.; Liang, J.; Li, Q. D. A highly selective and sensitive "on-off-on" fluorescent probe for detecting $\mathrm{Hg}(\mathrm{II})$ based on $\mathrm{Au} / \mathrm{N}$-doped carbon quantum dots. Sens. Actuators, B 2018, 255, 657-665.

(6) Bera, K.; Sau, A.; Mondal, P.; Mukherjee, R.; Mookherjee, D.; Metya, A.; Kundu, A. K.; Mandal, D.; Satpati, B.; Chakrabarti, O.; Basu, S. Metamorphosis of ruthenium-doped carbon dots: In search of the origin of photoluminescence and beyond. Chem. Mater. 2016, $28,7404-7413$

(7) Xu, Q.; Su, R. G.; Chen, Y. S.; Sreenivasan, S. T.; Li, N.; Zheng, X. S.; Zhu, J. F.; Pan, H. B.; Li, W. J.; Xu, C. M.; Xia, Z. H.; Dai, L. M. Metal charge transfer doped carbon dots with reversibly switchable, ultra-high quantum yield potoluminescence. ACS Appl. Nano Mater. 2018, 1, 1886-1893.

(8) Pakkath, S. A. R.; Chetty, S. S.; Selvarasu, P.; Murugan, A. V.; Kumar, Y.; Periyasamy, L.; Santhakumar, M.; Sadras, S. R.; Santhakumar, K. Transition metal ion $\left(\mathrm{Mn}^{2+}, \mathrm{Fe}^{2+}, \mathrm{Co}^{2+}\right.$, and $\left.\mathrm{Ni}^{2+}\right)$ doped carbon dots synthesized via microwave-assisted pyrolysis: A potential nanoprobe for magneto-fluorescent dual-modality bioimaging. ACS Biomater. Sci. Eng. 2018, 4, 2582-2596.

(9) Yao, Y. Y.; Gedda, G.; Girma, W. M.; Yen, C. L.; Ling, Y. C.; Chang, J. Y. Magnetofluorescent carbon dots derived from crab shell for targeted dual-modality bioimaging and drug delivery. ACS Appl. Mater. Interfaces 2017, 9, 13887-13899.

(10) Jia, Q.; Ge, J. C.; Liu, W. M.; Zheng, X. L.; Chen, S. Q.; Wen, Y. M.; Zhang, H. Y.; Wang, P. F. A Magnetofluorescent carbon dot assembly as an acidic $\mathrm{H}_{2} \mathrm{O}_{2}$-driven oxygenerator to regulate tumor hypoxia for simultaneous bimodal imaging and enhanced photodynamic therapy. Adv. Mater. 2018, 30, No. e1706090.

(11) Das, R. K.; Pramanik, A.; Majhi, M.; Mohapatra, S. Magnetic mesoporous silica gated with doped carbon dot for site-specific drug delivery, fluorescence, and MR imaging. Langmuir 2018, 34, 52535262.

(12) Nimi, N.; Saraswathy, A.; Nazeer, S. S.; Francis, N.; Shenoy, S. J.; Jayasree, R. S. Multifunctional hybrid nanoconstruct of zerovalent iron and carbon dots for magnetic resonance angiography and optical imaging: An In vivo study. Biomaterials 2018, 171, 46-56.

(13) Zhang, H. Y.; Wang, Y.; Xiao, S.; Wang, H.; Wang, J. H.; Feng, L. Rapid detection of $\mathrm{Cr}(\mathrm{VI})$ ions based on cobalt(II)-doped carbon dots. Biosens. Bioelectron. 2017, 87, 46-52.

(14) Shamsipur, M.; Barati, A.; Karami, S. Long-wavelength, multicolor, and white-light emitting carbon-based dots: Achievements made, challenges remaining, and applications. Carbon 2017, 124, 429-472.

(15) Ma, Y. S.; Cen, Y.; Sohail, M.; Xu, G. H.; Wei, F. D.; Shi, M. L.; Xu, X. M.; Song, Y. Y.; Ma, Y. J.; Hu, Q. A ratiometric fluorescence universal platform based on $\mathrm{N}, \mathrm{Cu}$ codoped carbon dots to detect metabolites participating in $\mathrm{H}_{2} \mathrm{O}_{2}$-generation reactions. ACS Appl. Mater. Interfaces 2017, 9, 33011-33019.

(16) Lin, T. R.; Zhong, L. S.; Chen, H.; Li, Z. H.; Song, Z. P.; Guo, L. Q.; Fu, F. F. A sensitive colorimetric assay for cholesterol based on the peroxidase-like activity of $\mathrm{MoS}_{2}$ nanosheets. Microchim. Acta 2017, 184, 1233-1237.

(17) Huang, Y.; Tan, J.; Cui, L. J.; Zhou, Z. D.; Zhou, S. F.; Zhang, Z. H.; Zheng, R.; Xue, Y. W.; Zhang, M. X.; Li, S. S.; Zhu, N. X.; Liang, J. T.; Li, G. L.; Zhong, L. P.; Zhao, Y. X. Graphene and Au NPs co-mediated enzymatic silver deposition for the ultrasensitive electrochemical detection of cholesterol. Biosens. Bioelectron. 2018, $102,560-567$.

(18) Zhang, F. M.; Ma, P. Y.; Deng, X. Y.; Sun, Y.; Wang, X. H.; Song, D. Q. Enzymatic determination of uric acid using water-soluble $\mathrm{CuInS} / \mathrm{ZnS}$ quantum dots as a fluorescent probe. Microchim. Acta 2018, 185, 499.

(19) Liu, Y. Y.; Li, H. C.; Guo, B.; Wei, L. J.; Chen, B.; Zhang, Y. Y. Gold nanoclusters as switch-off fluorescent probe for detection of uric acid based on the inner filter effect of hydrogen peroxide-mediated enlargement of gold nanoparticles. Biosens. Bioelectron. 2017, 91, 734-740.

(20) Kaushik, A.; Solanki, P. R.; Kaneto, K.; Kim, C.; Ahmad, S.; Malhotra, B. D. Nanostructured iron oxide platform for impedimetric cholesterol detection. Electroanalysis 2010, 22, 1045-1055.

(21) Yang, L. Q.; Huang, N.; Lu, Q. Q.; Liu, M. L.; Li, H. T.; Zhang, Y. Y.; Yao, S. Z. A quadruplet electrochemical platform for ultrasensitive and simultaneous detection of ascorbic acid, dopamine, uric acid and acetaminophen based on a ferrocene derivative functional $\mathrm{Au}$ NPs/carbon dots nanocomposite and grapheme. Anal. Chim. Acta 2016, 903, 69-80.

(22) Arya, S. K.; Solanki, P. R.; Singh, S.; Kaneto, K.; Pandey, M. K.; Datta, M.; Malhotra, B. D. Poly-(3-hexylthiophene) self-assembled monolayer based cholesterol biosensor using surface plasmon resonance technique. Biosens. Bioelectron. 2007, 22, 2516-2524.

(23) Xu, S. J.; Wang, Y. Q.; Zhou, D. Y.; Kuang, M.; Fang, D.; Yang, W. H.; Wei, S. J.; Ma, L. A novel chemiluminescence sensor for sensitive detection of cholesterol based on the peroxidase-like activity of copper nanoclusters. Sci. Rep. 2016, 6, No. 39157.

(24) Ahmad, R.; Tripathy, N.; Hahn, Y. B. High-performance cholesterol sensor based on the solution-gated field effect transistor fabricated with $\mathrm{ZnO}$ nanorods. Biosens. Bioelectron. 2013, 45, 281286.

(25) Li, X.-L.; Li, G.; Jiang, Y. Z.; Kang, D. Z.; Jin, C. H.; Shi, Q.; Jin, T. F.; Inoue, K.; Todoroki, K.; Toyo'oka, T.; Min, J. Z. Human nails metabolite analysis: A rapid and simple method for quantification of uric acid in human fingernail by high-performance liquid chromatography with UV-detection. J. Chromatogr. B: Anal. Technol. Biomed. Life Sci. 2015, 1002, 394-398.

(26) Du, F.; Min, Y.; Zeng, F.; Yu, C.; Wu, S. A targeted and FRET based ratiometric fluorescent nanoprobe for imaging mitochondrial hydrogen peroxide in living cells. Small 2014, 10, 964-972.

(27) Liu, F.; Bing, T.; Shangguan, D.; Zhao, M.; Shao, N. Ratiometric fluorescent biosensing of hydrogen peroxide and hydroxyl radical in living cells with lysozyme-silver nanoclusters: Lysozyme as stabilizing ligand and fluorescence signal unit. Anal. Chem. 2016, 88, 10631-10638.

(28) Song, Y. H.; Chen, J. Y.; Hu, D. Q.; Liu, F. F.; Li, P.; Li, H. B.; Chen, S. H.; Tan, H. L.; Wang, L. Ratiometric fluorescent detection of biomakers for biological warfare agents with carbon dots chelated europium-based nanoscale coordination polymers. Sens. Actuators, B 2015, 221, 586-592.

(29) Huang, S.; Wang, L. M.; Huang, C. S.; Su, W.; Xiao, Q. Labelfree and ratiometric fluorescent nanosensor based on aminofunctionalized graphene quantum dots coupling catalytic Gquadruplex/hemin DNAzyme for ultrasensitive recognition of human telomere DNA. Sens. Actuators, B 2017, 245, 648-655.

(30) Liu, J. W.; Luo, Y.; Wang, Y. M.; Duan, L. Y.; Jiang, J. H.; Yu, R. Q. Graphitic carbon nitride nanosheets-based ratiometric fluorescent probe for highly sensitive detection of $\mathrm{H}_{2} \mathrm{O}_{2}$ and glucose. ACS Appl. Mater. Interfaces 2016, 8, 33439-33445.

(31) Xiao, Q.; Liang, Y.; Zhu, F. W.; Lu, S. Y.; Huang, S. Microwaveassisted one-pot synthesis of highly luminescent $\mathrm{N}$-doped carbon dots for cellular imaging and multi-ion probing. Microchim. Acta 2017, 184, 2429-2438.

(32) Lan, M. H.; Di, Y. F.; Zhu, X. Y.; Ng, T. W.; Xia, J.; Liu, W. M.; Meng, X. M.; Wang, P. F.; Lee, C. S.; Zhang, W. J. A carbon dot-based fluorescence turn-on sensor for hydrogen peroxide with a photoinduced electron transfer mechanism. Chem. Commun. 2015, 51, 15574-15577. 
(33) Wang, R. X.; Wang, X. F.; Sun, Y. M. One-step synthesis of selfdoped carbon dots with highly photoluminescence as multifunctional biosensors for detection of iron ions and pH. Sens. Actuators, B 2017, 241, 73-79.

(34) Atchudan, R.; Edison, T. N. J. I.; Sethuraman, M. G.; Lee, Y. R. Efficient synthesis of highly fluorescent nitrogen-doped carbon dots for cell imaging using unripe fruit extract of Prunus mume. Appl. Surf. Sci. 2016, 384, 432-441.

(35) Yu, C. Y.; Xuan, T. T.; Chen, Y. W.; Zhao, Z. J.; Liu, X. X.; Lian, G. H.; Li, H. L. Gadolinium-doped carbon dots with high quantum yield as an effective fluorescence and magnetic resonance bimodal imaging probe. J. Alloys Compd. 2016, 688, 611-619.

(36) Hu, T. Y.; He, J.; Zhang, S. M.; Mei, X.; Zhang, W. K.; Liang, R. Z.; Wei, M.; Evans, D. G.; Duan, X. An ultrathin photosensitizer for simultaneous fluorescence imaging and photodynamic therapy. Chem. Commun. 2018, 54, 5760-5763.

(37) Hou, J.; Wang, L.; Zhang, P.; Xu, Y.; Ding, L. Facile synthesis of carbon dots in an immiscible system with excitation-independent emission and thermally activated delayed fluorescence. Chem. Commun. 2015, 51, 17768-17771.

(38) Huang, S.; Yang, E. L.; Yao, J. D.; Liu, Y.; Xiao, Q. Carbon dots doped with nitrogen and boron as ultrasensitive fluorescent probes for determination of $\alpha$-glucosidase activity and its inhibitors in water samples and living cells. Microchim. Acta 2018, 185, 394.

(39) Huang, S.; Yang, E. L.; Yao, J. D.; Liu, Y.; Xiao, Q. Red emission nitrogen, boron, sulfur co-doped carbon dots for "on-off-on" fluorescent mode detection of $\mathrm{Ag}^{+}$ions and L-cysteine in complex biological fluids and living cells. Anal. Chim. Acta 2018, 1035, 192202.

(40) Zeng, Y. W.; Ma, D. K.; Wang, W.; Chen, J. J.; Zhou, L.; Zheng, Y. Z.; Yu, K.; Huang, S. M. N, S Co-doped carbon dots with orange luminescence synthesized through polymerization and carbonization reaction of amino acids. Appl. Surf. Sci. 2015, 342, 136-143.

(41) Ma, Y.; Chen, Y. L.; Liu, J. J.; Han, Y. X.; Ma, S. D.; Chen, X. G. Ratiometric fluorescent detection of chromium(VI) in real samples based on dual emissive carbon dots. Talanta 2018, 185, 249-257.

(42) Liu, Y.; Duan, W. X.; Song, W.; Liu, J. J.; Ren, C. L.; Wu, J.; Liu, D.; Chenm, H. L. Red emission B, N, S-co-doped carbon dots for colorimetric and fluorescent dual mode detection of $\mathrm{Fe}^{3+}$ ions in complex biological fluids and living cells. ACS Appl. Mater. Interfaces 2017, 9, 12663-12672.

(43) Gupta, V.; Chaudhary, N.; Srivastava, R.; Sharma, G. D.; Bhardwaj, R.; Chand, S. Luminscent graphene quantum dots for organic photovoltaic devices. J. Am. Chem. Soc. 2011, 133, 99609963.

(44) Ju, B.; Wang, Y.; Zhang, Y. M.; Zhang, T.; Liu, Z. H.; Li, M. J.; Zhang, S. X. A. Photostable and low-toxic yellow-green carbon dots for highly selective detection of explosive 2,4,6-trinitrophenol based on the dual electron transfer mechanism. ACS Appl. Mater. Interfaces 2018, 10, 13040-13047.

(45) Chen, S.; Yu, Y. L.; Wang, J. H. Inner filter effect-based fluorescent sensing systems: A review. Anal. Chim. Acta 2018, 999, $13-26$.

(46) Liu, H.; Xu, C.; Bai, Y.; Liu, L.; Liao, D.; Liang, J.; Liu, L.; Han, $\mathrm{H}$. Interaction between fluorescein isothiocyanate carbon dots: Inner filter effect and fluorescence resonance energy transfer. Spectrochim. Acta, Part A 2017, 171, 311-316.

(47) Wang, W. T.; Ji, X.; Kapur, A.; Zhang, C. Q.; Mattoussi, H. A multifunctional polymer combining the imidazole and zwitterion motifs as a biocompatible compact coating for quantum dots. J. Am. Chem. Soc. 2015, 137, 14158-14172.

(48) Hu, Y.; Zhang, Z. Determination of free cholesterol based on a novel flow-injection chemiluminescence method by immobilizing enzyme. Luminescence 2008, 23, 338-343. 